\title{
Personality traits and preferred exercise environment of fitness club members
}

\author{
Cassio M. Meira Jr. ${ }^{1, *}$, Ana C. Gomes ${ }^{1}$, Maria T. Cattuzzo ${ }^{2}$, Carmen Flores-Mendoza ${ }^{3}$, Laura \\ Tosini $^{1}$, and Marcelo Massa ${ }^{1}$ \\ ${ }^{I}$ School of Arts, Sciences, and Humanities, University of Sao Paulo, Sao Paulo, Brazil, ${ }^{2}$ Superior School of Physical Educa- \\ tion, University of Pernambuco, Pernambuco, Brazil; and ${ }^{3}$ College of Philosophy and Human Sciences, Federal University \\ of Minas Gerais, Belo Horizonte, Brazil
}

Copyright: (c) 2020 C. M. Meira et al. This is an open access article licensed under the Creative Commons Attribution License (https://creativecommons.org/licenses/by/4.0/).

\begin{abstract}
Background: Fitness environment can be adjusted to better combine with salient personality characteristics. Nevertheless, previous research seems to neglect the personal characteristics of individuals. It would be beneficial if the fitness club environment will be adapted to the personality characteristics of their visitors because these changes could increase adherence to various exercise programs. However, there is a lack of research on individual preferences and predispositions of fitness club members. Objective: The purpose of the present study was to assess associations between personality traits and physical/social environment preferences of fitness club members. Methods: A total of 613 fitness club members ( 286 men and 327 women), age $(M \pm S D) 29.2 \pm 10.1$ years, answered 15 questions regarding physical and social environment preferences and the short version of the NEO-Five Factor Inventory. Results: The path analysis showed that a general personality factor, represented by Conscientiousness, Extraversion, and Agreeableness, predicted preferred environment in a fitness club setting, especially concerning to performing new/ repeated exercises and social aspects of exercise. Furthermore, Openness and Neuroticism did not correlate to fitness club exercise practice preferences. Conclusions: The study found evidence suggesting that a general personality factor represented by Extraversion, Conscientiousness, and Agreeableness can predict preferred fitness environment regarding the performance of new/repeated exercises and social aspects of the exercise.
\end{abstract}

Keywords: preferences, individual differences, physical activity, gym

\section{Introduction}

It is widely known that substantial psychological and physiological benefits are related to regular physical activity and exercise (Burke, Carron, Eys, Ntoumanis, \& Estabrooks, 2006; Daley \& Maynard, 2003; Kantomaa, Tammelin, Ebeling, \& Stamatakis, 2015). Physical inactivity is the fourth leading risk factor for death worldwide (World Health Organization, 2018), and, should insufficient levels of physical activity be held, the desired $10 \%$ global reduction in physical inactivity levels in 2025 will not be achieved (Guthold, Stevens, Riley, \& Bull, 2018). In this context, adherence is an important issue regarding exercise. For example, those who decide to engage in a regular physical activity program tend to quit within the first six months

\footnotetext{
* Address for correspondence: Cassio M. Meira Jr., School of Arts, Sciences, and Humanities, University of Sao Paulo, 1000 Arlindo Bettio Av, 03828-000 Sao Paulo, Brazil. E-mail: cmj@usp.br
}

(Buckworth, Dishman, O'Connor, \& Tomporowski, 2013; Nigg, Borrelli, Maddock, \& Dishman, 2008). Thus, it seems reasonable that if the health goal pursued worldwide is to increase participation of individuals in regular physical activity (World Health Organization, 2018), it is crucial to add to the research agenda the investigation of individual factors that influence the adherence to physical activity programs.

Participation in exercise programs enables coexistence, fun, social inclusion, social identity, feeling of belonging, and entertainment (Burke et al., 2006; Kantomaa et al., 2015; Parfitt \& Gledhill, 2004; Rhodes \& Smith, 2006). In addition, people engaged with physical activity programs self-declared greater improvements in positive affect when practicing high preference exercise modes (Hutchinson \& Sherman, 2014; Miller, Bartholomew, \& Springer, 2005). These psychological and social characteristics of exercise can be related to an important individual factor that has been examined regarding regular exercise: the 
personality trait. The Five-Factor Model (FFM; Costa \& McCrae, 1992, 1995), also known as the Big-5, has arguably been the most dominant instrument used in the study of personality traits. This model assumes the existence of five relatively stable dimensions - Openness, Conscientiousness, Extraversion, Agreeableness and Neuroticism. The Openness trait indicates how open-minded a person is. Conscientiousness reflects the tendency to be responsible, organized, hard-working. Extraversion entails characteristics of creativity, activity and the search for stimuli. Agreeableness is related to being trustworthy, altruistic, honest, and cooperative. Neuroticism is associated with emotional (in)stability, anxiety, and vulnerability (Meira, Gomes, Gomes, Santos, Basso, \& Tani, 2019).

These traits have been identified as predictors of behavior patterns, which can be applied to a wide range of situations (Ozer \& Benet-Martínez, 2006), including physical activity settings (Butković, Hlupić, \& Bratko, 2017; Rhodes, 2006; Rhodes \& Smith, 2006; Wilson \& Dishman, 2015). Studies' findings on personality traits and physical activity have suggested that individuals with high levels of Extraversion and Conscientiousness and low levels of Neuroticism are most likely to have a physically active lifestyle (Butković et al., 2017; Hoyt, Rhodes, Hausenblas, \& Giacobbi, 2009; Rhodes \& Smith, 2006; Wilson \& Dishman, 2015). Considering the fundamental characteristics of Extraversion (i.e., the tendency to seek excitement and to be sociable, assertive, and energetic) and Conscientiousness (i.e., the tendency to be self-disciplined, and achievementoriented), it is plausible to admit that those with high scores on these dimensions are more prone to adhere to physical activity. Moreover, individuals who have low levels of Neuroticism tend to be emotionally stable and to have lower anxiety levels (Rhodes \& Smith, 2006). This predisposition seems to facilitate readiness for physical activity or the search for practice opportunities (Wilson \& Dishman, 2015). However, given that Neuroticism is related to an increased capacity for autonomic response to intense stimuli and predisposition to negative effects (Eysenck, 2017), lower scores on this trait would help to explain the permanence in exercise programs, even if the individual perceives as negative the physiological response to increased stimulation during exercise.

Physical activity preferences may include several general attributes, such as exercise type, surrounding environment, and trait characteristics. Nevertheless, previous research on the topic seems to neglect the personal characteristics of individuals (Cohen-Mansfield, Marx, Biddison, \& Guralnik, 2004; Rhodes \& Smith, 2006). In this vein, physical activity interventions seem to be most beneficial when adapted to particular preferences (Burke et al., 2006), such as personality traits. The present study is aimed at assessing associations between personality traits and physical and social environment preferences in fitness club members. As multiple aspects of personality traits and exercise were addressed in this paper, we did not develop a set of a priori hypotheses; instead, we raised the following general expectation which was built upon previously available research: aspects of social behavior, practice supervision, and exercise type are associated with Extraversion, Conscientiousness, and Neuroticism (Bogg, 2008; Courneya \& Hellsten, 1998; Rhodes, 2006; Rhodes \& Smith, 2006; Wilson \& Dishman, 2015).

\section{Method}

\section{Participants}

Participants $(N=613)$ were 286 men and 327 women, aged from 15 to 66 years, $84 \%$ of young adults (18-40 years old), $5 \%$ of adolescents (15-17 years old), and $11 \%$ middle-aged/elderly (41-66 years old). Mean age of the sample was 29.2 years, with a standard deviation of 10.1 years. They were enrolled in five fitness clubs in the metropolitan area of São Paulo, Brazil. We did not stratify the sample by gender and age in favor of statistical power.

University Ethics Committee approved the study, CAAE 49991115.3.0000.5390, under the observance that participants and/or parents/tutors read and signed an informed consent, which assured anonymity and confidentiality.

\section{Measures and procedures}

The short version of the NEO-Five Factor Inventory (John \& Srivastava, 1999), validated for the Brazilian population (Andrade, 2008), was used to measure the five personality traits (Openness, Conscientiousness, Extraversion, Agreeableness, Neuroticism). The questionnaire consists of 44 questions using a Likert scale, which ranges from 1 (strongly disagree) to 5 (strongly agree).

Inspired by previously published questionnaires (Burke et al., 2006), the Preferred Exercise Environment Questionnaire (PEQ) was elaborated for the present study. The PEQ is a self-reporting non-dimensional questionnaire composed by the following fifteen questions in this exact order: 1. Do you prefer practicing alone? 2. Do you get bothered when people are around while practicing physical activity? 3. Do you prefer practicing with the teachers around? 4 . Do you prefer the same professor for your practicing? 5. Do you give your opinion about the practice? 6. Do you usually talk to other people during practice? 7. Do you 
strictly follow the instructions given to practice? 8. Do you prefer activities with repeated movement? 9. Do you like varied practices? 10. Do you like practicing with familiar movements? 11. Do you like motivational stimuli from others during practice? 12. Do you prefer practicing surrounded by mirrors? 13. Do you prefer music during your practicing? 14. Do you prefer bright light during practice? 15 . Do you practice in a hurry? Participants had three options of responding to each question: "yes", "no", or "indifferent". The questionnaire was conceived with general questions associated with the five personality traits on physical activity practice in the fitness club.

The Big Five Inventory and the PEQ were administered in situ and via the website.

\section{Analysis}

The two instruments (Big Five and PEQ) used in the present study were psychometrically analyzed. The Cronbach's alpha of the Big Five Inventory was .723, an acceptable internal consistency coefficient, however, the corrected item-total correlation of 16 items was either negative or close to zero. The exploratory factor analysis (EFA), using Maximum Likelihood (ML) extraction (EFA-ML) indicated 10 factors using all 44 items and 2 factors for each personality dimension when EFA-ML was conducted for each dimension. After the exclusion of these 16 items, the internal consistency coefficient increased to .802 . Then, the MPlus software (Version 8.5 for Microsoft Windows; Muthén \& Muthén, Los Angeles, CA, USA) was used to run both EFA (ML and rotation Varimax) and confirmatory factor analysis (CFA) to identify the factor model with better adjustment to the data. The cutoff values considered acceptable for the measurement model test are $\mathrm{CMIN} / d f<5.0, \mathrm{CFI}>.90$, RMSEA $<.08$, and SRMR <.08 (Bentler, 1990); where RMSEA is root mean squared error approximation, CMIN/df is minimum discrepancy per degree of freedom, CFI is comparative fit index, and SRMR is standardized root mean squared residual.

Regarding the personality questionnaire, a five-factor model with 25 items (five items for each personality trait) explained $39.2 \%$ of the variance and presented better adjustment indexes: CMIN/df $=515.920 / 185$, $\mathrm{RMSEA}=.054, \mathrm{CFI}=.918, \mathrm{SRMR}=.035($ Table A1 $)$.

Regarding the PEQ, the internal consistency (Cronbach's alpha) was .665 after the exclusion of two items (5 and 7) with low item-total correlation $(<.150)$. To investigate the factor structure, an exploratory factor analysis (Maximum Likelihood analysis, Varimax rotation) was conducted. The results indicated four components responsible for $48.8 \%$ of the total variance. The model adjustment determination was based on comparing the indexes of two CFAs (3-factor and 4-factor model). The 3-factor model had an acceptable adjustment $(\mathrm{CMIN} / d f=2.73 . \mathrm{CFI}=.902, \mathrm{RMSEA}=.053$, SRMR = .038), however the four factor-model showed the best adjustment $(\mathrm{CMIN} / d f=1.93, \mathrm{CFI}=.960$, RMSEA $=.039$, SRMR $=.027)$. These factors related to the preferred environment (PE) were named as supervised exercising (PE1; items 3 and 4), performing new or repeated exercises (PE2; items 8, 9, and 10), social aspects of exercise (PE3; items 6, 11 and 13), and non-supervised exercising (PE4; items 1, 2, 12, and 14), see Table A2.

Finally, a latent trajectory analysis was conducted to evaluate assumed causal relationships (direct and indirect) between the indicators studied.

\section{Results}

Table 1 shows the descriptive statistics for the five variables of interest. The correlation matrix is also shown.

Table 1 reveals that personality traits Openness, Conscientiousness, Extraversion, Agreeableness, and Neuroticism share common components (significant correlations between .376 and .445) and preferred fitness environment PE1, PE2, PE3 and PE4 also share common components (significant correlations between .151 and .325); PE1 is not related to any personality trait. Table 1 also shows that PE4 is not related to any personality trait, and that the personality traits Openness and Neuroticism are not related to any PE factor. Additionally, the personality traits Conscientiousness, Extraversion, and Agreeableness have positive correlations with PE2 (performing exercises) and PE3 (social aspects of exercise).

When considering the results presented in Table 1, personality traits, except Neuroticism, can be represented by a general personality factor. This general factor was identified within the five-factor model's studies (Erdle, Irwing, Rushton, \& Park, 2010; Musek, 2007). According to Table 1, personality traits Conscientiousness, Extraversion, and Agreeableness are related to preferred fitness environments, especially PE2 and PE3.

Next, the variables of interest were submitted to a path analysis considering the personality (PERS) and the preferred fitness environment (PE) as latent variables. Results are shown in Figure 1. Note that nonsignificant relationships have been removed from the model for simplicity, but they were reported in Table 1. Figure 1 shows that personality, represented by traits Conscientiousness, Extraversion, and Agreeableness, predicts preferred fitness environment $(\beta=.493$, $p<.001)$ based on performing exercise (PE2) and 
Table 1

Personality traits (Openness, Conscientiousness, Extraversion, Agreeableness, Neuroticism) and preferred fitness environment

\begin{tabular}{|c|c|c|c|c|c|c|c|c|c|}
\hline Variable & 1 & 2 & 3 & 4 & 5 & 6 & 7 & 8 & 9 \\
\hline 1. Openness & - & $.400 * *$ & $.445 * *$ & $.376 * *$ & $.168 * *$ & -.016 & .027 & .057 & -.052 \\
\hline 2. Conscientiousness & & - & $.389 * *$ & $.379 * *$ & .048 & .050 & $.104^{*}$ & $.080 *$ & .046 \\
\hline 3. Extraversion & & & - & $.436 * *$ & .002 & .006 & $.111^{* *}$ & $.243 * *$ & -.021 \\
\hline 4. Agreeableness & & & & - & -.086 & .051 & $.092 *$ & $.174 * *$ & .006 \\
\hline 5. Neuroticism & & & & & - & .078 & -.057 & .027 & .048 \\
\hline 6. PE1 & & & & & & - & $.268 * *$ & $.225 * *$ & $.241 * *$ \\
\hline 7. PE2 & & & & & & & - & $.236 * *$ & $.325 * *$ \\
\hline 8. PE3 & & & & & & & & - & $.151^{* *}$ \\
\hline 9. PE4 & & & & & & & & & - \\
\hline$M$ & 19.8 & 21.1 & 19.3 & 21.4 & 14.4 & 3.3 & 5.1 & 4.2 & 7.0 \\
\hline$S D$ & 3.4 & 2.8 & 3.7 & 2.9 & 3.9 & 1.3 & 1.9 & 1.3 & 1.8 \\
\hline
\end{tabular}

Note. $\quad$ PE1 = supervised exercise; PE2 = performing new or repeated exercises; PE3 = social aspects of exercise; PE4 = non-supervised exercise. ${ }^{*} p<.05,{ }^{* *} p<.01$.

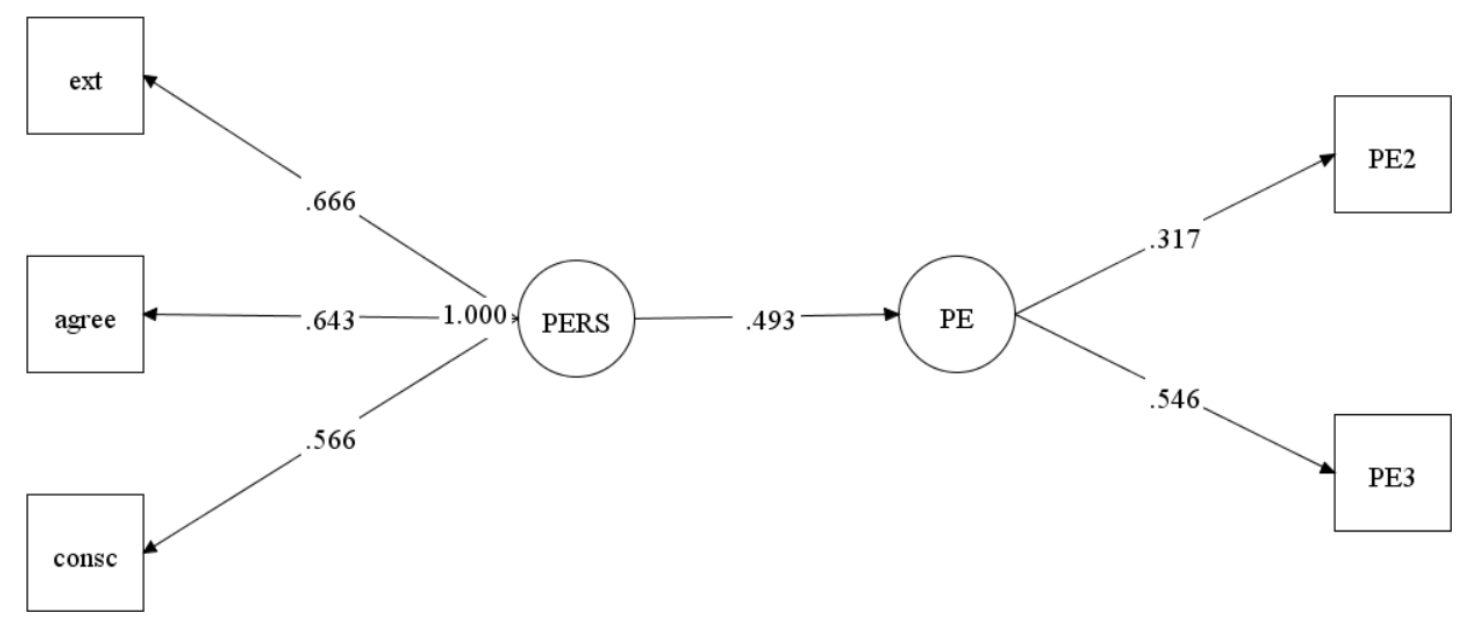

Figure 1. Standardized path coefficient relating personality PERS (at latent level) to preferred fitness environment PE (at latent level). Ext $=$ Extraversion; agree $=$ Agreeableness; consc $=$ Conscientiousness; PE2 = performing new or repeated exercises; PE3 = social aspects of exercise.

social aspects of exercise (PE3). The proportion of the variance $\left(R^{2}\right)$ for the dependent variable (PE) explained by the independent variable (PERS) was $24.3 \%$. The adjustment indexes for this model were great: $\chi^{2}=2.957, d f=4, p=.565$, RMSEA $=.00,95 \%$ 95\% confiderence interval RMSEA [0.000, 0.053], $\mathrm{CFI}=1.000, \mathrm{TLI}=1.000, \mathrm{SRMR}=.012$.

\section{Discussion}

Previous research on physical activity preferences seems to be focused especially on general attributes, not to the personal characteristics of the individuals (Cohen-Mansfield et al., 2004). From an individual differences perspective, if someone can adapt instruction to personal exercise preferences, the feeling of enjoyment and the adherence to exercise programs can be promoted (Burke et al., 2006; Kantomaa et al., 2015). The present study aimed to tackle this topic by assessing relationships between personality traits and exercise preferences in fitness club members.

Our latent model revealed that a general personality factor predicts the preferred fitness environment, especially concerning the performance of new/repeated exercises (PE2) and social aspects of exercise (PE3). Performing new or repeated exercises (PE2) is associated with repetition, variation, and familiarity of movements, while social aspects of exercise (PE3) involve interactions with other people and preference for music 
during practice. We expected that, in some way, personality traits could be related to PE1, PE2, PE3 and/ or PE4. For instance, extraverts, self-disciplined, and emotionally stable individuals would be most likely to have a physically active lifestyle. Therefore, they would endorse positive behaviors of involvement, adherence, and maintenance of physical activity (Butković et al., 2017; Rhodes, 2006; Wilson \& Dishman, 2015).

Our results indicated that Conscientiousness, Extraversion, and Agreeableness were positively correlated with the performance of new or repeated exercises (PE2) and social aspects of exercise (PE3). The PE2 factor, performing new or repeated exercises, is linked to repetition and variation during the exercise. In the learning of a sequential-timing motor task, it was detected more pronounced contextual interference effects for introverts when compared to extraverts (Meira, Fairbrother, \& Perez, 2015), while introverted elderly women showed worse speed-accuracy tradeoff performance than their introverted counterparts (Meira, Moraes, Moura, Ávila, Tosini, \& Magalhaes, 2018). Both studies implied handling variations of a motor task, which were for introverts more difficult to cope. Our findings are in line with this notion that Extraversion is related to variation and repetition during exercise practice.

The relationships of Conscientiousness, Extraversion, and Agreeableness regarding the third PE factor social aspects of exercise seem to be robust. Extraverted, self-disciplined, and agreeable fitness club members tend to show behaviors associated with acoustic stimuli, which are most associated with facets of activity, excitement seeking, positive emotions, dutifulness, interaction with other people, and motivational feedback (Wang, Begley, Hui, \& Lee, 2012). Listening to music while practicing exercise has been considered a high source of motivation which boosts acute performance (Alter et al., 2015; Hutchinson \& Sherman, 2014). In addition, encouragement, as a manifestation of motivation, has the potential to increase self-efficacy and performance (Tuckman \& Sexton, 1991).

Even though previous research indicates that exercise behavior is negatively correlated with Neuroticism (Rhodes \& Smith, 2006; Wilson \& Dishman, 2015), we found that this trait was not related to exercise practice in a fitness club context. Further, the personality trait Openness is not linked to any PE factor, that is, the fact of being open to experiences bears little relationship with exercise practice.

Despite previous research (Burke et al., 2006; Cohen-Mansfield et al., 2004; Ginis, Jung, \& Gauvin, 2003; Hawkley, Thisted, \& Cacioppo, 2009; Kantermann et al., 2012; Katula \& McAuley, 2001), we identified that the supervision of a teacher (PE1) and being alone during practice/practicing surrounded by mirrors and under bright light (PE4) were not associated with personality traits.

We recognize limitations in the present study. Although the sample is similar in size to previous studies on the topic, it is only representative of fitness club members from the metropolitan area of Sao Paulo, Brazil. In addition, several biases may have affected the results due to the acquisition of data via self-reports.

\section{Conclusions}

In summary, our study gives new evidence to suggest a general personality factor encompassing Conscientiousness, Extraversion, and Agreeableness that can predict preferred exercise environment of fitness club members, especially concerning to the performance of new/repeated exercises and social aspects of exercise.

\section{Acknowledgments}

We are grateful to Aline Alcântara, Evandro Cardoso, and Camila Pessoa for the help with data collection.

\section{Conflict of interest}

There were no conflicts of interest.

\section{References}

Alter, D. A., O’Sullivan, M., Oh, P. I., Redelmeier, D. A., Marzolini, S., Liu, R., ... Bartel, L. R. (2015). Synchronized personalized music audio-playlists to improve adherence to physical activity among patients participating in a structured exercise program: A proof-of-principle feasibility study. Sports Medicine - Open, 1, 23.

Andrade, J. M. (2008). Validity evidence from the Five Factor Inventory for Brazil. (Unpublished doctoral dissertation). University of Brasília, Brasília, Brazil.

Bentler, P. M. (1990). Comparative fit indexes in structural models. Psychological Bulletin, 107, 238-246.

Bogg, T. (2008). Conscientiousness, the transtheoretical model of change, and exercise: A neo-socioanalytic integration of trait and social-cognitive frameworks in the prediction of behavior. Journal of Personality, 76, 775-801.

Buckworth, J., Dishman, R. K., O’Connor, P. J., \& Tomporowski, P. D. (Eds). (2013). Exercise psychology (2nd ed.). Champaign, IL: Human Kinetics.

Burke, S. M., Carron, A. V., Eys, M. A., Ntoumanis, N., \& Estabrooks, P. A. (2006). Group versus individual approach? A meta-analysis of the effectiveness of interventions to promote physical activity. Sport and Exercise Psychology Review, 2, 19-35. 
Butković, A., Hlupić, T. V., \& Bratko, D. (2017). Physical activity and personality: A behaviour genetic analysis. Psychology of Sport and Exercise, 30, 128-134.

Cohen-Mansfield, J., Marx, M. S., Biddison, J. R., \& Guralnik, J. M. (2004). Socio-environmental exercise preferences among older adults. Preventive Medicine, 38, 804-811. Costa, P. T., \& McCrae, R. R. (1992). NEO-PI$R$ professional manual: Revised NEO Personality Inventory (NEO-PI-R) and NEO-Five Factor Inventory (NEO-FFI). Odessa, FL: Psychological Assessment Resources.

Costa, P. T., \& McCrae, R. R. (1995). Domains and facets: Hierarchical personality assessment using the Revised NEO Personality Inventory. Journal of Personality Assessment, 64, 21-50.

Courneya, K. S., \& Hellsten, L. A. (1998). Personality correlates of exercise behavior, motives, barriers, and preferences: An application of the five-factor model. Personality and Individual Differences, 24, 625-633.

Daley, A. J., \& Maynard, I. W. (2003). Preferred exercise mode and affective responses in physically active adults. Psychology of Sport and Exercise, 4, 347-356.

Erdle, S., Irwing, P., Rushton, J. P., \& Park, J. (2010). The general factor of personality and its relation to self-esteem in 628,640 internet respondents. Personality and Individual Differences, 48, 343-346.

Eysenck, H. J. (2017). The biological basis of personality. New York, NY: Routledge.

Ginis, K. A. M., Jung, M. E., \& Gauvin, L. (2003). To see or not to see: Effects of exercising in mirrored environments on sedentary women's feeling states and self-efficacy. Health Psychology, 22, 354-361.

Guthold, R., Stevens, G. A., Riley, L. M., \& Bull, F. C. (2018). Worldwide trends in insufficient physical activity from 2001 to 2016: A pooled analysis of 358 populationbased surveys with 1.9 million participants. The Lancet Global Health, 6, e1077-e1086.

Hawkley, L. C., Thisted, R. A., \& Cacioppo, J. T. (2009). Loneliness predicts reduced physical activity: Crosssectional \& longitudinal analyses. Health Psychology, 28, 354-363.

Hoyt, A. L., Rhodes, R. E., Hausenblas, H. A., \& Giacobbi, P. R., Jr. (2009). Integrating five-factor model facet-level traits with the theory of planned behavior and exercise. Psychology of Sport and Exercise, 10, 565-572.

Hutchinson, J. C., \& Sherman, T. (2014). The relationship between exercise intensity and preferred music intensity. Sport, Exercise, and Performance Psychology, 3, 191-202.

John, O. P., \& Srivastava, S. (1999). The big five trait taxonomy: History, measurement, and theoretical perspectives. In L. A. Pervin \& O. P. John (Eds.), Handbook of personality: Theory and research (2nd ed., pp. 102-138). New York, NY: Guilford Press.

Kantermann, T., Forstner, S., Halle, M., Schlangen, L., Roenneberg, T., \& Schmidt-Trucksäss, A. (2012). The stimulating effect of bright light on physical performance depends on internal time. PLOS ONE, 7(7), e40655.
Kantomaa, M. T., Tammelin, T., Ebeling, H., \& Stamatakis, E. (2015). High levels of physical activity and cardiorespiratory fitness are associated with good self-rated health in adolescents. Journal of Physical Activity and Health, 12, 266-272.

Katula, J. A., \& McAuley, E. (2001). The mirror does not lie: Acute exercise and self-efficacy. International Journal of Behavioral Medicine, 8, 319-326.

Meira, C. M., Jr., Fairbrother, J. T., \& Perez, C. R. (2015). Contextual interference and introversion/extraversion in motor learning. Perceptual and Motor Skills, 121, 447-460.

Meira, C. M., Jr., Gomes, A. C., Gomes, F., Santos, S., Basso, L., \& Tani, G. (2019). Personality traits and gross motor performance in children from Muzambinho/MG. Brazilian Journal of Motor Behavior, 13, 124-132.

Meira, C. M., Jr., Moraes, R., Moura, M., Ávila, L. T. D., Tosini L., \& Magalhães, F. H. (2018). Extraversion/introversion and age-related differences in speed-accuracy tradeoff. Revista Brasileira de Medicina do Esporte, 24, 225-229.

Miller, B. M., Bartholomew, J. B., \& Springer, B. A. (2005). Post-exercise affect: The effect of mode preference. Journal of Applied Sport Psychology, 17, 263-272.

Musek, J. (2007). A general factor of personality: Evidence for the Big One in the five-factor model. Journal of Research in Personality, 41, 1213-1233.

Nigg, C. R., Borrelli, B., Maddock, J., \& Dishman, R. K. (2008). A theory of physical activity maintenance. Applied Psychology: An International Review, 57, 544-560.

Ozer, D. J., \& Benet-Martínez, V. (2006). Personality and the prediction of consequential outcomes. Annual Review of Psychology, 57, 401-421.

Parfitt, G., \& Gledhill, C. (2004). The effect of choice of exercise mode on psychological responses. Psychology of Sport and Exercise, 5, 111-117.

Rhodes, R. E. (2006). The built-in environment: The role of personality and physical activity. Exercise and Sport Sciences Reviews, 34, 83-88.

Rhodes, R. E., \& Smith, N. E. I. (2006). Personality correlates of physical activity: A review and meta-analysis. British Journal of Sports Medicine, 40, 958-965.

Tuckman, B. W., \& Sexton, T. L. (1991). The effect of teacher encouragement on student self-efficacy and motivation for self-regulated performance. Journal of Social Behavior and Personality, 6, 137-146.

Wang, H., Begley, T., Hui, C., \& Lee, C. (2012). Are the effects of conscientiousness on contextual and innovative performance context specific? Organizational culture as a moderator. International Journal of Human Resource Management, 23, 174-189.

Wilson, K. E., \& Dishman, R. K. (2015). Personality and physical activity: A systematic review and meta-analysis. Personality and Individual Differences, 72, 230-242.

World Health Organization. (2018). Health statistics and information systems. Retrieved from https://www.who.int/ healthinfo/global_burden_disease/en/ 


\section{Appendix}

\section{Table A1}

Results of the Big Five Inventory using exploratory factor analysis (Maximum Likelihood extraction, Varimax rotation)

\begin{tabular}{|c|c|c|c|c|c|}
\hline Construct/Item & $M$ & $S D$ & Loading & A & $\begin{array}{c}\text { Explained } \\
\text { variance } \\
(\%)\end{array}$ \\
\hline Openness & & & & .720 & 3.4 \\
\hline You are original, always with new ideas & 3.93 & 0.8 & .628 & & \\
\hline You are inventive, creative & 3.89 & 0.9 & .705 & & \\
\hline You have a fertile imagination & 4.01 & 1.0 & .426 & & \\
\hline You are ingenious, someone who likes to deeply analyze things & 3.86 & 1.0 & .379 & & \\
\hline You like to reflect, play with ideas & 4.08 & 0.9 & .406 & & \\
\hline Conscientiousness & & & & .677 & 19.8 \\
\hline You are meticulous, detail-oriented at work & 4.18 & 0.9 & .435 & & \\
\hline You insist until you complete the task or the job & 4.34 & 0.8 & .541 & & \\
\hline You do things efficiently & 4.24 & 0.7 & .608 & & \\
\hline You are a reliable worker & 4.62 & 0.7 & .535 & & \\
\hline You make plans and follow them to the letter & 3.69 & 1.0 & .511 & & \\
\hline Extraversion & & & & .719 & 4.6 \\
\hline You are talkative, communicative & 3.91 & 1.1 & .673 & & \\
\hline You are assertive, you are not afraid to express what you feel & 3.69 & 1.1 & .329 & & \\
\hline You are sociable and outgoing & 4.02 & 1.0 & .799 & & \\
\hline You have a lot of energy and vitality & 3.95 & 0.9 & .409 & & \\
\hline You convey a lot of enthusiasm & 3.68 & 0.9 & .409 & & \\
\hline Agreeableness & & & & .685 & 7.9 \\
\hline You like to cooperate with others & 4.36 & 0.8 & .675 & & \\
\hline You are helpful and help others & 4.42 & 0.7 & .631 & & \\
\hline You are kind and considerate of others & 4.42 & 0.7 & .605 & & \\
\hline You are generally trustworthy & 4.64 & 0.6 & .352 & & \\
\hline You have the ability to forgive easily & 3.59 & 1.2 & .399 & & \\
\hline Neuroticism & & & & .665 & 3.5 \\
\hline You are depressed and sad & 1.90 & 1.1 & .470 & & \\
\hline You are temperamental and change your mind easily & 2.67 & 1.2 & .360 & & \\
\hline You get tense often & 3.09 & 1.2 & .786 & & \\
\hline You get nervous easily & 2.76 & 1.2 & .752 & & \\
\hline You worry about everything & 4.00 & 1.0 & .305 & & \\
\hline
\end{tabular}


Table A2

Results of the Preferred Exercise Environment using exploratory factor analysis (Maximum Likelihood extraction, Varimax rotation)

\begin{tabular}{|c|c|c|c|c|}
\hline Construct/Item & $M$ & $S D$ & Loading & $\begin{array}{c}\text { Explained } \\
\text { variance }(\%)\end{array}$ \\
\hline PE1 - supervised exercise & & & & 11.7 \\
\hline Do you prefer practicing with the teachers around? & 1.65 & 0.8 & .343 & \\
\hline Do you prefer the same professor for your practicing? & 1.69 & 0.8 & .964 & \\
\hline PE2 - performing new or repeated exercises & & & & 10.9 \\
\hline Do you prefer activities with repeated movement? & 1.82 & 0.8 & .633 & \\
\hline Do you like varied practices? & 1.47 & 0.8 & .644 & \\
\hline Do you like practicing with familiar movements? & 1.84 & 0.9 & .440 & \\
\hline PE3 - social aspects of exercise & & & & 5.8 \\
\hline Do you usually talk to other people during practice? & 1.58 & 0.6 & .479 & \\
\hline Do you like motivational stimuli from others during practice? & 1.44 & 0.7 & .502 & \\
\hline Do you prefer music during your practicing? & 1.19 & 0.5 & .275 & \\
\hline PE4 - non-supervised exercise & & & & 3.8 \\
\hline Do you prefer practicing alone? & 1.85 & 0.7 & .369 & \\
\hline $\begin{array}{l}\text { Do you get bothered when people are around while practicing physi- } \\
\text { cal activity? }\end{array}$ & 1.92 & 0.5 & .275 & \\
\hline Do you prefer practicing surrounded by mirrors? & 1.57 & 0.8 & .393 & \\
\hline Do you prefer bright light during practice? & 1.69 & 0.8 & .403 & \\
\hline Cronbach's alpha for the total scale & .661 & & & \\
\hline
\end{tabular}

